University of Nebraska - Lincoln

DigitalCommons@University of Nebraska - Lincoln

USDA Wildlife Services - Staff Publications

U.S. Department of Agriculture: Animal and Plant Health Inspection Service

$9-1-2021$

\title{
Spatial variation in direct and indirect contact rates at the wildlife- livestock interface for informing disease management
}

\author{
Anni Yang \\ Colorado State University, yangann1@colostate.edu \\ Raoul K. Boughton \\ Range Cattle Research and Education Center \\ Ryan S. Miller \\ USDA Centers for Epidemiology and Animal Health \\ Bethany Wight \\ Range Cattle Research and Education Center \\ Wesley M. Anderson \\ Range Cattle Research and Education Center \\ Follow this and additional works at: https://digitalcommons.unl.edu/icwdm_usdanwrc \\ Part of the Natural Resources and Conservation Commons, Natural Resources Management and

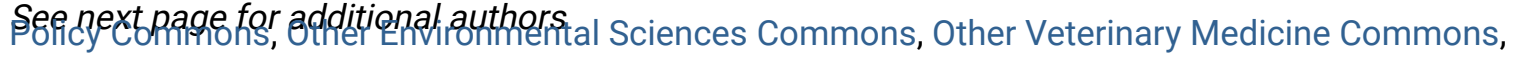 \\ Population Biology Commons, Terrestrial and Aquatic Ecology Commons, Veterinary Infectious Diseases \\ Commons, Veterinary Microbiology and Immunobiology Commons, Veterinary Preventive Medicine, \\ Epidemiology, and Public Health Commons, and the Zoology Commons
}

Yang, Anni; Boughton, Raoul K.; Miller, Ryan S.; Wight, Bethany; Anderson, Wesley M.; Beasley, James C.; VerCauteren, Kurt C.; Pepin, Kim M.; and Wittemyer, George, "Spatial variation in direct and indirect contact rates at the wildlife-livestock interface for informing disease management" (2021). USDA Wildlife Services - Staff Publications. 2482.

https://digitalcommons.unl.edu/icwdm_usdanwrc/2482

This Article is brought to you for free and open access by the U.S. Department of Agriculture: Animal and Plant Health Inspection Service at DigitalCommons@University of Nebraska - Lincoln. It has been accepted for inclusion in USDA Wildlife Services - Staff Publications by an authorized administrator of DigitalCommons@University of Nebraska - Lincoln. 


\section{Authors}

Anni Yang, Raoul K. Boughton, Ryan S. Miller, Bethany Wight, Wesley M. Anderson, James C. Beasley, Kurt C. VerCauteren, Kim M. Pepin, and George Wittemyer 


\title{
Spatial variation in direct and indirect contact rates at the wildlife-livestock interface for informing disease management
}

\author{
Anni Yang ${ }^{\mathrm{a}, \mathrm{b}, *}$, Raoul K. Boughton ${ }^{\mathrm{c}}$, Ryan S. Miller ${ }^{\mathrm{d}}$, Bethany Wight ${ }^{\mathrm{c}}$, Wesley M. Anderson ${ }^{\mathrm{c}}$, \\ James C. Beasley $^{\mathrm{e}}$, Kurt C. VerCauteren ${ }^{\mathrm{b}}$, Kim M. Pepin ${ }^{\mathrm{b}}$, George Wittemyer ${ }^{\mathrm{a}}$ \\ ${ }^{a}$ Department of Fish, Wildlife, and Conservation Biology, Colorado State University, Fort Collins, CO, 80523, USA \\ ${ }^{\mathrm{b}}$ National Wildlife Research Center, United States Department of Agriculture, Animal and Plant Health Inspection Service, Wildlife Services, 4101 Laporte Avenue, Fort \\ Collins, CO, 80521, USA \\ ${ }^{\mathrm{c}}$ Wildlife Ecology and Conservation, Range Cattle Research and Education Center, University of Florida, 3401 Experiment Station, Ona, FL, 33865, USA \\ ${ }^{\mathrm{d}}$ Center for Epidemiology and Animal Health, United States Department of Agriculture, Animal and Plant Health Inspection Service, Veterinary Service, 2150 Centre \\ Avenue, Fort Collins, CO, 80526, USA \\ e Savannah River Ecology Laboratory, Warnell School of Forestry and Natural Resources, University of Georgia, PO Drawer E, Aiken, SC, 29802, USA
}

\section{A R T I C L E I N F O}

\section{Keywords:}

Contact rates

Indirect contact

Cattle supplement

Wildlife-livestock interface

Wild pigs

\begin{abstract}
A B S T R A C T
Little is known about disease transmission relevant contact rates at the wildlife-livestock interface and the factors shaping them. Indirect contact via shared resources is thought to be important but remains unquantified in most systems, making it challenging to evaluate the impact of livestock management practices on contact networks. Free-ranging wild pigs (Sus scrofa) in North America are an invasive, socially-structured species with an expanding distribution that pose a threat to livestock health given their potential to transmit numerous livestock diseases, such as pseudorabies, brucellosis, trichinellosis, and echinococcosis, among many others. Our objective in this study was to quantify the spatial variations in direct and indirect contact rates among wild pigs and cattle on a commercial cow-calf operation in Florida, USA. Using GPS data from 20 wild pigs and 11 cattle and a continuous-time movement model, we extracted three types of spatial contacts between wild pigs and cattle, including direct contact, indirect contact in the pastoral environment (unknown naturally occurring resources), and indirect contact via anthropogenic cattle resources (feed supplements and water supply troughs). We examined the effects of sex, spatial proximity, and cattle supplement availability on contact rates at the species level and characterized wild pig usage of cattle supplements. Our results suggested daily pig-cattle direct contacts occurred only occasionally, while a significant number of pig-cattle indirect contacts occurred via natural resources distributed heterogeneously across the landscape. At cattle supplements, more indirect contacts occurred at liquid molasses than water troughs or molasses-mineral block tubs due to higher visitation rates by wild pigs. Our results can be directly used for parameterizing epidemiological models to inform risk assessment and optimal control strategies for controlling transmission of shared diseases.
\end{abstract}

\section{Introduction}

The role of wildlife in the (re)emergence of livestock diseases has been increasing due to global climate change, human encroachment on wildlife habitat, and changes in wildlife distributions and demographics (Jones et al., 2013; Miller et al., 2017; Patz et al., 1996). In the United States, it has been suggested that $\sim 80 \%$ of reportable livestock diseases have a potential wildlife component and over $40 \%$ are zoonotic (Miller et al., 2013). Disease management at the wildlife-livestock interface requires understanding of pathogen transmission among multiple host species (Johnson et al., 2015; Wiethoelter et al., 2015). A major component of transmission is contact, which can occur directly between hosts or indirectly via media, like environmental sources (Craft, 2015). Mechanisms and behaviors that facilitate contact among hosts are varied, i.e. direct contact often requires spatial and temporal co-location between hosts, while indirect contact can simply require spatial co-location within a certain time window (Godfrey, 2013). This distinction in host contact mechanisms can result in variations in contact rates within and between host species and across landscape, which can structure pathogen transmission. Understanding the magnitude of

\footnotetext{
* Corresponding author at: Department of Fish, Wildlife, and Conservation Biology, Colorado State University, Fort Collins, CO, 80523, USA.

E-mail address: yangann1@colostate.edu (A. Yang).
} 
variation across different types of contact (direct versus indirect) among host populations is crucial for optimizing disease control strategies in multi-host systems (Boehm et al., 2009).

Wild pigs (Sus scrofa; other common names: wild hog, feral swine, and feral hog; Keiter et al., 2016), descended from both domestic pigs and Eurasian wild boar, are the most abundant free-ranging, invasive ungulate in North America (Bevins et al., 2014). Recently, concerns regarding the potential veterinary and public health threats of wild pigs in North America have increased given their continuously expanding distribution and the ability to transmit numerous diseases to livestock, including African swine fever, Trichinellosis, and brucellosis (Lewis et al., 2019; Miller et al., 2017).

Cattle health is often impacted by infectious diseases from wildlife reservoirs including wild pigs, which can transmit fatal diseases to cattle, such as tuberculosis and pseudorabies (Miller et al., 2017). Several previous studies have empirically investigated contact between wild boars/pigs and cattle to inform risk of cross-species disease transmission. For example, Barasona et al. (2013) estimated fine-scale spatial overlap of cattle and wild boar and found interactions were most likely to occur in marsh-shrub ecotone and permanent water sources. Triguero-Ocaña et al. (2019) quantified encounters between 12 cattle and 14 wild boar using GPS collars and indicated an interaction rate of 1.3-1.5 times per day per pair. Cooper et al. (2010) found direct contacts were rare and occurred primarily at water sources, while indirect contacts occurred near irrigated forage fields and along ranch roads. A limitation to this previous work is the reliance on contact defined using discrete GPS fixes with varying fix resolution and differentiated thresholds in space and time to describe a contact. Such an approach may underestimate the amount of contact (by only measuring contact at fixed time points) or overestimate contact (by using distance thresholds that are too far for a transmission-relevant contact). Additionally, other previous work estimated daily contacts at an aggregate level, without consideration of spatial variations in contact rates (Boehm et al., 2009; Drewe et al., 2013) that could impact disease persistence or spatial disease dynamics. Such coarse scale analysis can limit our ability to optimize the distribution of interventions. Contact estimates that overcome these limitations and provide a more realistic approximation of true contact rates and variation are needed to improve spatial predictions of disease risk using epidemiological models.

Providing feed and supplements (e.g., minerals) to cattle is a common approach to improve cattle performance, increase economic return, and manage their behavior (Kunkle et al., 2000). However, anthropogenic feed and supplements at ranches with low biosecurity measures, no fences, or fences unable to separate cattle and wildlife may attract wildlife species and facilitate both direct and indirect contacts, which can increase the risk of disease transmissions across host species. This has been found in several disease systems on cattle farms, including brucellosis, bTB, and foot-mouth disease (Bates et al., 2003; Kukielka et al., 2013; Lavelle et al., 2014; Schumaker et al., 2012). Moreover, indirect contact could be particularly important in diseases with causal pathogens that can persist for long periods in the environment (Yang et al., 2020). Besides artificial food sources, naturally occurring resources such as forage, cover, and water can also be contaminated and lead to cross-species transmission via indirect contact (zu Dohna et al., 2014). However, little research to date has addressed this component in transmission systems due to the complexity of measuring and quantifying indirect contact at naturally occurring resource attractants on the landscape (Boehm et al., 2009; Drewe et al., 2013; Wilber et al., 2019; Yang et al., 2021).

In this study, we use a continuous-time movement model of pig and cattle Global Positioning System (GPS) data to derive time specific estimates of space use not constricted by the discrete nature of location sampling by GPS telemetry. From these movement paths, we quantify transmission relevant intra- and inter-specific contacts. Our main objective was to estimate the spatial variations in contact rates at the wild pig-cattle interface, including both "pig-pig" and "pig-cattle" contacts ("cattle-cattle" contacts were not evaluated) and the factors that shape the contact rates, to inform disease management. Three types of contacts were estimated : direct contact, indirect contact via naturally occurring resources, and indirect contact via cattle supplements (including indirect contacts via both cattle feed and water troughs). We also quantified wild pig visitation rates to different types of cattle supplements to provide information that cattle managers can apply to reduce contact rates among cattle and wild pigs.

\section{Material and methods}

\subsection{Study area and data collection}

Our study was conducted on the Archbold's Biological Station - Buck Island Ranch (ABIR) in Florida, USA. ABIR is a $42.3 \mathrm{~km}^{2}$ commercial beef cow-calf operation managed at commercial production levels with an average standing inventory of $\sim 3000$ head of cattle. The ranch is typical of a sub-tropical region cow-calf operation with high primary productivity and high grazing intensity. In Florida, breeds of beef cattle are dominated by angus braham crossbreed dams. Cattle are grazed across a mosaic of natural and altered habitats including improved pasture, semi-native prairie and flatwood rangelands, with embedded oak-palm hammock forests, and wetlands (Swain et al., 2013). A low rotation grazing frequency, every 30-60 days across multiple (2-3) pastures, is a common best practice in the region for these expensive ranches. Detailed description of livestock operations and a 5 year average stocking rates for ABIR of 347 Animal Use Days (AUD) $\mathrm{ha}^{-1} \mathrm{yr}^{-1}$ on improved pastures and 152 AUD ha $^{-1} \mathrm{yr}^{-1}$ on semi-native rangelands can be found in Kohmann et al. (2021). Typical of large ranches worldwide the mosaic of habitats continues to support high wildlife species diversity, and in Florida includes wild pigs. The population density of the adult wild pigs at the ABIR ranges $\sim 1.90-2.95$ per $\mathrm{km}^{2}$ (P. Schlichting, unpub. data). The study site encompasses $\sim 10 \mathrm{~km}^{2}$ area that represents the commonly found mixture of habitats found on Florida ranches, sub-divided into multiple pastures, in which both the focal cattle herd grazed, and focal wild pigs were captured (Fig. 2E-F).

We deployed GPS collars (Catlog GPS device and Lotek LMRT3 VHF Collars, Lotek $\odot$, WA, US) on 20 adult, free-ranging wild pigs (aged by weights; 15 females and 5 males) and 11 random selected adult cattle from the $\sim 400$ head focal cow herd. During the capture, we intended to cover most social groups of the wild pigs across the focal pastures (given pre-collaring camera survey), and in some social groups we collared multiple adults (see the overall social group information in Table S1). The location measurement error of GPS fixes for collars was determined against a true location recorded using a GeoExplorer 6000 Trimble (Model 88,950) at $\sim 15 \mathrm{~cm}$ accuracy. Location error for open and closed canopy habitats was $6.6 \mathrm{~m} \pm 6.9 \mathrm{~m}$ and $8.6 \mathrm{~m} \pm 7.7 \mathrm{~m}$, respectively. Collars were programmed to record GPS fixes with a 30 -min interval from April $7^{\text {th }}-$ September $7^{\text {th, }}$ 2017. In coordination with these collar deployments, anthropogenic feed and water point sources within the study pastures were mapped and time available recorded. There were 4 permanent wells that supply continuous fresh water to cattle troughs, in addition 5 supplemental molasses block mineral locations (i.e., mineral station) and 6 liquid molasses feeding stations (molasses station) were available for varying time lengths with the first supplements distributed June $5^{\text {th }}$ in the study area. Mineral tubs are a hard candy version with more mineral, while liquid molasses is a higher energy and protein supplement.

\subsection{Extract contacts based on GPS data and continuous-time movement model}

A continuous-time correlated random walk model (CTCRW; Johnson et al., 2008) was employed to fit the discrete GPS fixes with positional dilution of precision values less than 10 (D'Eon and Delparte, 2005) to predict animal locations at any time between the start and end of the 
tracking period. CTCRW is derived from a continuous-time Ornstein-Uhlenbeck velocity process, which incorporates autocorrelation into both the speed and direction of movement (Johnson et al., 2008). The model was formulated in a state-space framework that allows parameter estimation based on maximum likelihood using Kalman filter and predictions on unknown animal locations during tracking (Johnson et al., 2008). Given the stochasticity embedded in the CTCRW models, there is variation in model fitting and parameter estimation across runs. To capture this variation, we fit 200 CTCRW models to each animal using the "crawl" R-package (Johnson et al., 2008; R Core Team, 2019) and selected the best 100 models based on Akaike Information Criterion. We then used the parameters estimated from the top selected models to predict and interpolate the movement trajectory for each animal at a temporal scale of one minute and used the median of the interpolated trajectories with $95 \%$ confidence intervals to represent each animals' continuous movement path (Fig. 1A).

Using the interpolated movement locations, we identified three types of pig-pig and pig-cattle contacts: direct contact, indirect contact via naturally occurring resources (i.e., natural resource-mediated contact), and indirect contact via supplements (i.e., supplement-mediated contact). Given different intermediate sources that induce indirect contact, we separated indirect contact into these two classes to better distinguish the resource - indirect contact interaction. Direct contacts were recorded when two animals were in the same place at the same time according to their interpolated continuous-time movement trajectories (Fig. 1B).

Indirect contacts were recorded when two individuals crossed the same location within a time window that approximates pathogen survival in the environment (Schauber et al., 2007). In this study, we used a temporal segregation of 7 and 30 days to represent pathogens that persist in the environment for a relatively short period, such as pseudorabies virus (Freund, 1981; Schoenbaum et al., 1991), relative to those that remain infectious for weeks or months, like Mycobacterium bovis (the causative agent of bTB) (Fine et al., 2011) and Brucella spp. (Aune et al., 2012), respectively. Given different intermediate sources that induce indirect contact, we classified indirect contact into two classes, supplement-mediated indirect contact and natural resource-mediated indirect contact (i.e., indirect contact unrelated to water troughs and supplements).

We defined supplement-mediated indirect contact as any pair of animals that overlapped with (contacted) the same supplement station/ water trough or its 45-m buffer neighborhood within 7-day and 30-day intervals (Fig. 1D). We considered a larger area rather than the single point location of the supplement station because 1 ) there were several resource tubs deployed at the same station and 2) the contact site is often more than just the tubs and should be a larger area of concentrated use (Cross et al., 2007).

One challenge inferring indirect contacts in the environment is that individuals may engage in different behaviors in different settings such that some are conducive to shedding and transmission while others are not. For example, when the two hosts run by the same location there may not be the same opportunity for indirect transmission than when two hosts spend time foraging or wallowing in the same location. Thus, considering all co-location data (e.g., Cooper et al., 2010) within the time frame of pathogen persistence could overestimate indirect contact. Another approach has been to record indirect contacts only at specific locations or resources where indirect transmission is expected to be likely, and placing contact recording devices at these locations (Drewe et al., 2013; Yang et al., 2021). However, this approach requires comprehensive knowledge of the ecosystem and may underestimate indirect contacts across the landscape since other indirect contacts can occur at unknown natural resources. Thus, to estimate indirect contact rates throughout the study site while filtering out co-locations that might not be relevant to disease transmission, we constrained estimates of indirect contact to areas with high use $\left(90^{\text {th }}\right.$ quantile of visitation as defined below) by host species.
To extract those high use areas, we first gridded (30-m resolution) the study area (Hulbert, 2001) and then calculated visitation rates to grid cells based on the interpolated animal movement trajectories separately for wild pigs and cattle. We then re-scaled the visitation rate $(v)$ to grid cells for wild pigs and cattle to be between 0 and 1 by $\frac{v-v_{\min }}{v_{\max }-v_{\min }}$ to generate 'probability of visitation' surfaces on the same scale for both host species. Given that the movement trajectory was interpolated into every minute, the higher probability of visitation of a cell also indicated a larger proportion of time spent in the area and thus higher chance of contamination. Specifically, to extract potential locations of pig-pig natural resource-mediated indirect contact, we used a probability surface of wild pig visitation rate, while for the pig-cattle natural resource-mediated indirect contact, we averaged the visitation probability surfaces for wild pigs and cattle where the two species overlapped to indicate the intensity of space use for both species. We defined the high use areas that could induce epidemiologically relevant natural resource-mediated indirect contact (i.e., those that could be contaminated by infected animals and cause pathogen transmission) as the grid cells with a probability of visitation greater than the 0.9 quantile. The 0.9 cutoff was selected as a conservative threshold to delineate the high-use areas (Morris et al., 2016; Wilson et al., 2014). We then assigned any pig-pig or pig-cattle pair visitation to those high-use areas within 7-day or 30-day time intervals as natural resource-mediated indirect contacts.

During the study period, the collared cattle were managed and moved across nine fenced pastures every $\sim 5-30$ days to minimize pasture damage and maximize grazing potential (routine rotational cattle management). During each routine period the cattle were in a different pasture, we expected the opportunity for contact with collared pigs to change. Thus, we divided the study period into different time windows based on when cattle were in different pastures (Table S2). We used those predefined periods as useful subsets of the GPS-extracted contact events to aggregate the contact rates for each unique pig-pig and pig-cattle pair.

\subsection{Quantify effects of biological factors on contacts}

We analyzed the effects of different factors, including sex, spatial proximity, and supplement deployment on three response variables for pig-cattle and pig-pig contacts: direct contacts, natural resourcemediated indirect contacts, and supplement-mediated indirect contacts. All the potential covariates that were used to account for those effects were reported in Table 1 with the detailed descriptions and summary statistics. We identified social group membership using HR overlap (e.g. within-group: HR overlap >0.5; between-group: HR overlap $<0.5$ ) (Gabor et al., 1999; Yang et al., 2021), because 1) the social group and HR overlap were largely redundant with high correlation of $>$ $0.68 ; 2)$ the HR overlap metric in different time frames can capture the potential fission-fusion dynamics of sociality in the wild pigs over time (temporal group switching behaviors) and represent group cohesion; 3) this approach allows a direct comparison between pig-pig and pig-cattle models. Additionally, given social group (i.e., HR metrics) was accounted for as a fixed effect, we included individual-level random effects to account for individual variation in pig-pig contact/visitation models. Individual random effects were also included in pig-cattle contact models.

\subsubsection{Inferring direct contact rates}

To quantify and compare the effects of sex, spatial proximity, and supplement availability on the contact structure of pig-pig and pig-cattle direct contacts, we employed a probabilistic framework to estimate weighted contact networks by considering pairwise contacts (Yang et al., 2021). We used a mixed-effect Poisson hurdle model (see model specifications in Supplementary Material 1) with a binomial hurdle component and a Poisson component to model the probability of contact 
A

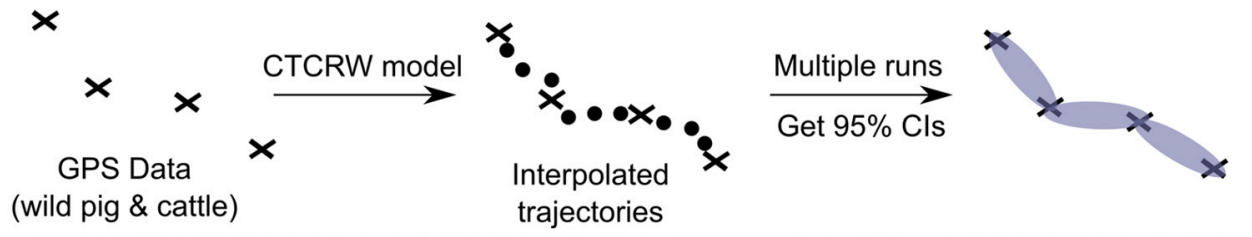

2) Define different types of contacts
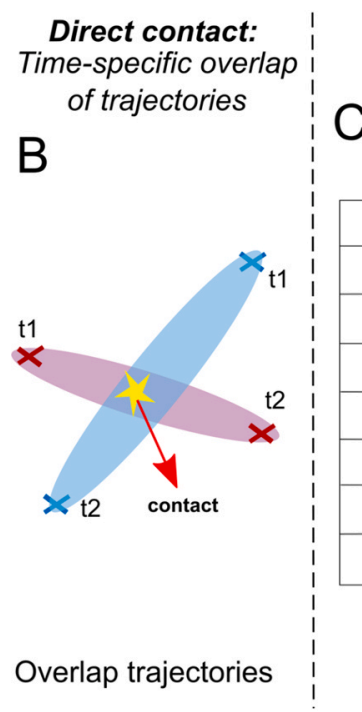

1) Interpolate trajectories

2) Define different types of contacts

Indirect contact:

Temporally segregated overlap of trajectories

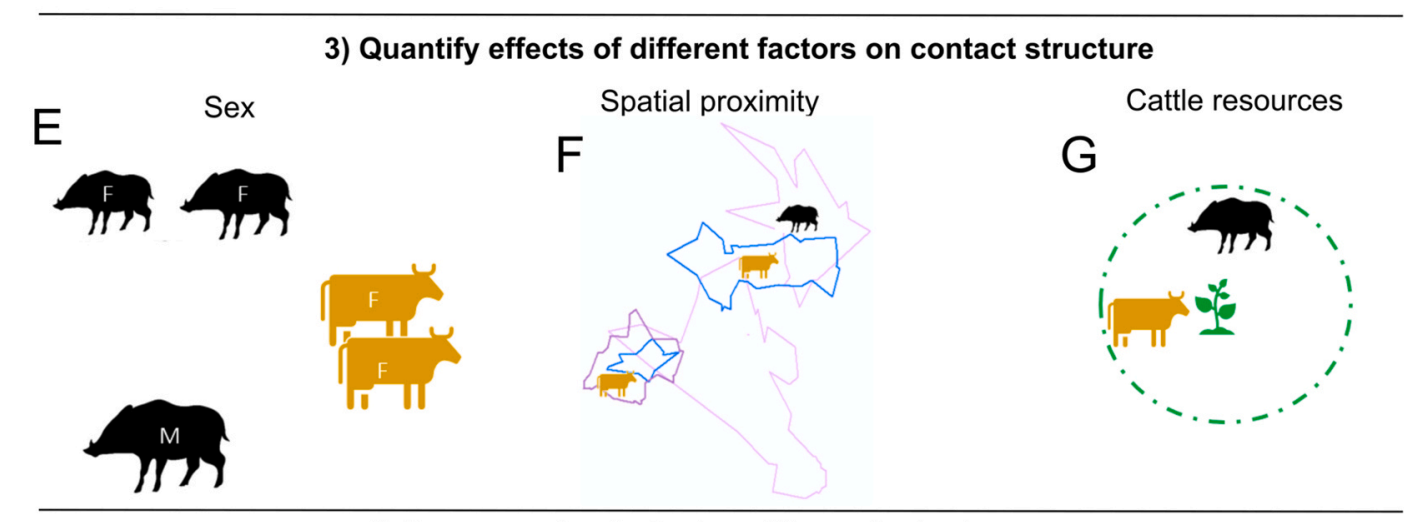

Indirect contact via natural resources

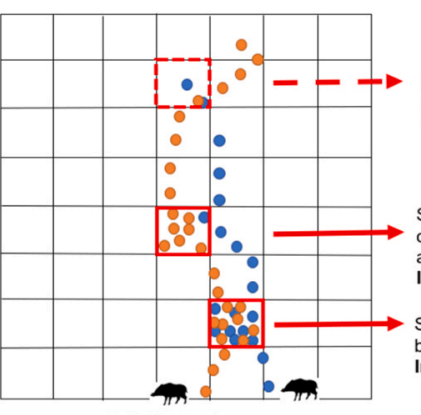

visitation rate map

High-use areas (over $90 \%$ of usage) $=$ potential indirect contact location

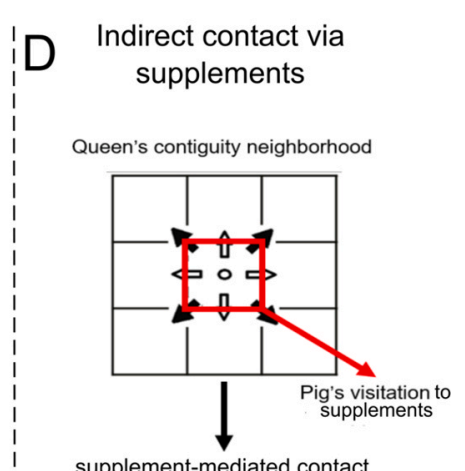

supplement-mediated contact

Neighborhood effects of cattle supplements

\section{3) Quantify effects of different factors on contact structure}

G
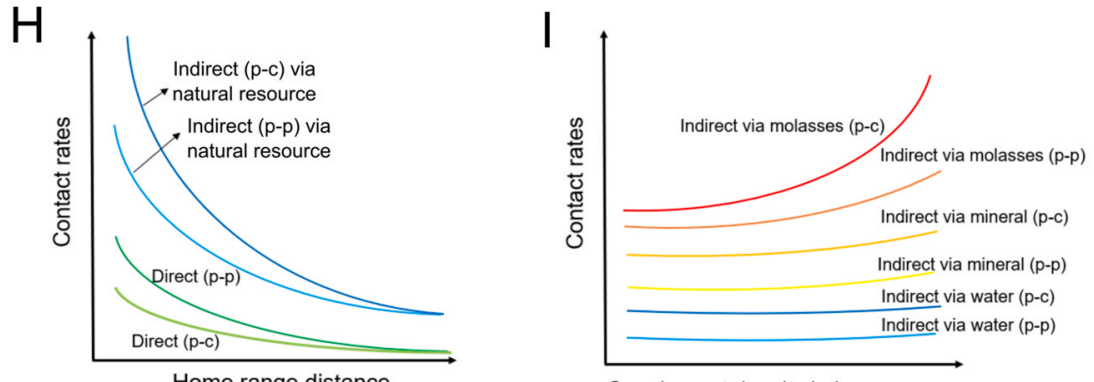

Supplement density in home range

Fig. 1. Conceptual framework of the analysis. (A) We fit the continuous-time random walk models (CTCRW) to GPS movement data from 20 wild pigs and 11 cattle to interpolate minute resolution movement trajectories with $95 \%$ confidence intervals. (B) We defined direct contacts between animals based on time-specific overlap of the interpolated trajectories, (C) natural resource-mediated indirect contact as temporally segregated overlap of trajectories on the high-use areas on the landscape, and (D) indirect contacts via supplements as temporally segregated overlap of trajectories at supplement/water trough locations and their contiguous local neighborhood (Queen's neighbors). We quantified effects of (E) sex, (F) spatial proximity of animals, and (G) supplement locations on the pig-pig and pig-cattle contact structure. (H-I) We compared pig-pig and pig-cattle contact rates (expected) as the functional responses to different factors, e.g. home range distance and supplement density in home range. 
A

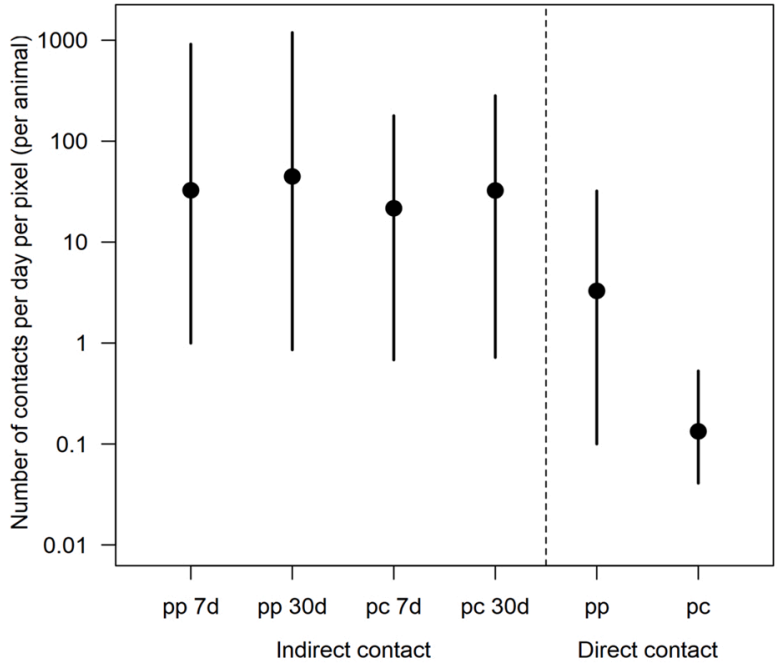

C

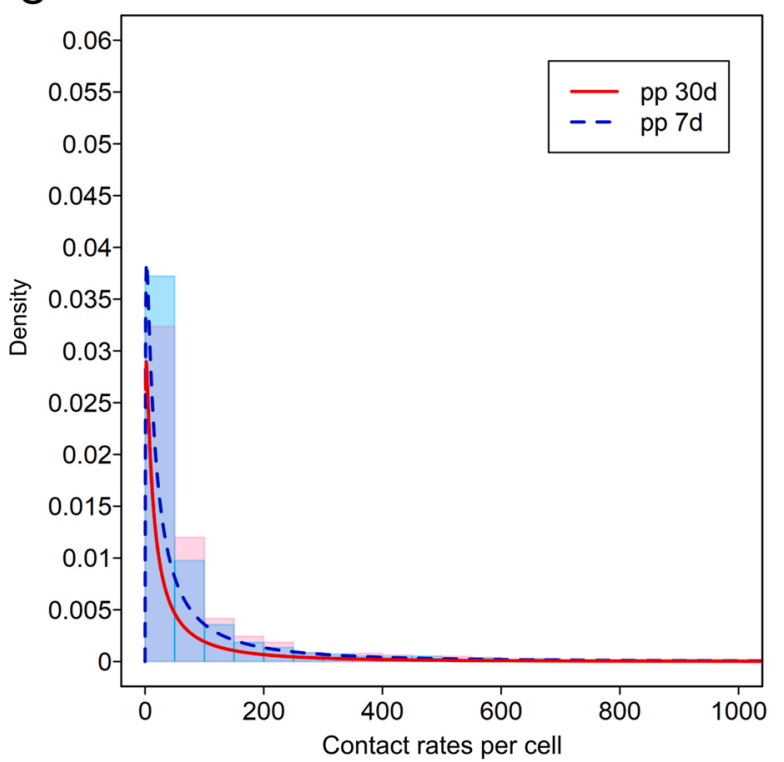

E
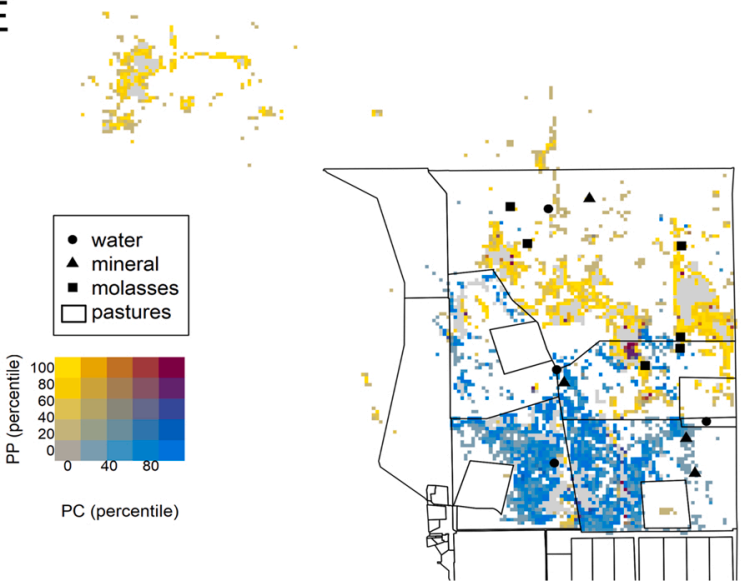

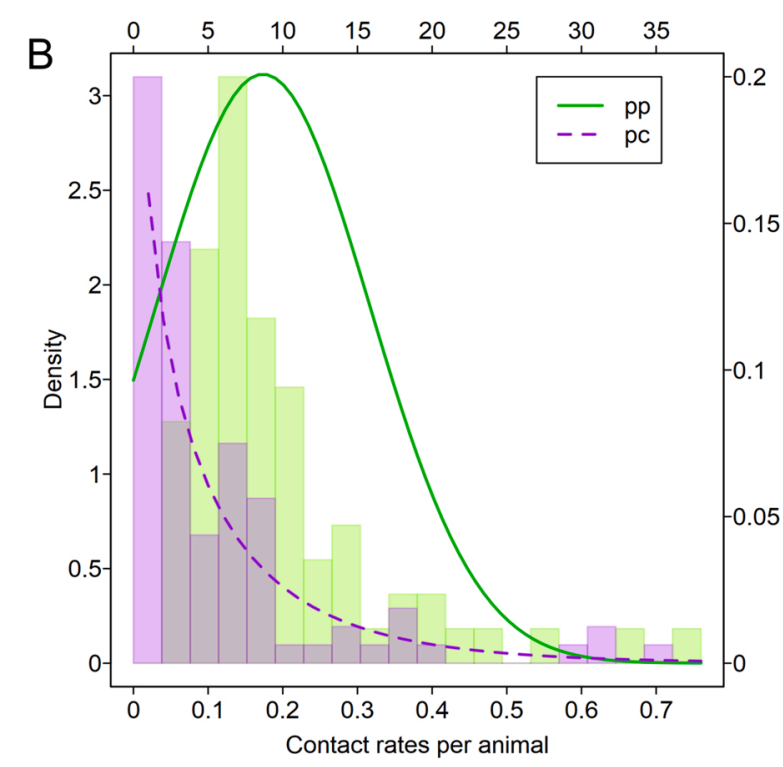

D

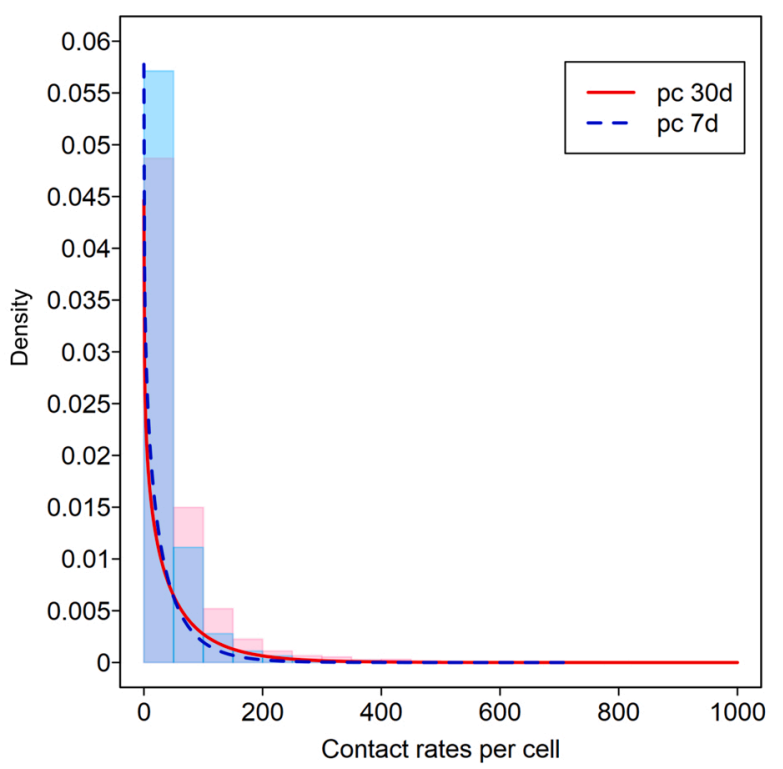

$\mathrm{F}$

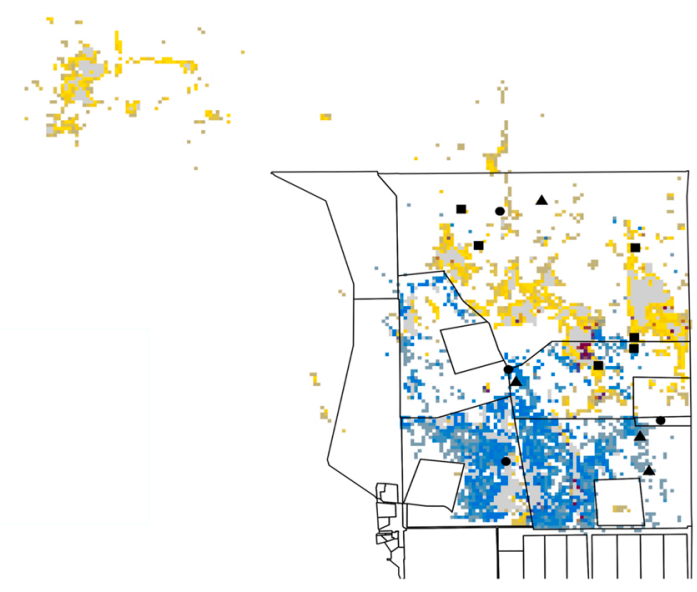


Fig. 2. Summary statistics of the contact rates for different types of contact. (A) The median and $95 \%$ quantile of the contact rates (number of contacts per animal) for pig-pig (pp) direct contact and pig-cattle (pc) direct contact; and indirect contacts at 7-day time interval (7d), or 30-day time interval (30d). (B) Probability distribution of pig-pig (Normal distribution; mean $=0.18$, sd $=0.13$ ) and pig-cattle (Weibull distribution; shape $=0.83$, scale $=0.39$ ) direct contact rates for the medians shown in A. Primary Y-axis and lower X-axis are for pig-cattle contact rate, while secondary Y-axis and upper X-axis are for pig-pig contact rate. (C) Probability distribution of the contact rates (truncated at 1000; range of 30-day interval: [0.09, 20236.89]; range of 7-day interval: [0.002, 10129.93]) for pig-pig natural resource-mediated indirect contact with the 7-day (Lognormal distribution; mean $=3.5$, $\mathrm{sd}=1.7$ ) and 30-day (Lognormal distribution; mean $=3.8$, sd $=1.7$ ) time intervals at each pixel. (D) Probability distribution of the contact rates for pig-pig natural resource-mediated indirect contact with the 7-day (Lognormal distribution; mean $=3.5, \mathrm{sd}=1.7$ ) and 30-day (Lognormal distribution; mean $=3.8$, sd $=1.7$ ) time intervals at each pixel. (E) Spatial distributions of pig-pig and pigcattle natural resource-mediated indirect contact with a 7-day time interval. (F) Spatial distributions of the frequency of pig-pig and pig-cattle natural resourcemediated indirect contact with a 30-day time interval.

Table 1

The descriptions and summary statistics of the covariates being used in the study. For the numerical variables, the descriptive statistics of median values and $95 \%$ quantiles were reported in fourth column, while the categories were presented for categorical variables.

\begin{tabular}{|c|c|c|c|}
\hline Variables & Description & Formulation & $\begin{array}{l}\text { Descriptive Statistics } \\
\text { (numerical)/ categories } \\
\text { (categorical) }\end{array}$ \\
\hline sex pair ${ }^{a}$ & $\begin{array}{l}\text { a factor where levels represent the sex of a unique pair of } \\
\text { animals }\end{array}$ & $\begin{array}{l}\text { For example, an "F_M" level represents a pair of female and } \\
\text { male animals. }\end{array}$ & $\begin{array}{l}\text { Pig-pig: F_M; F_F; M_M } \\
\text { Pig-cattle (cows): F_F; M_F }\end{array}$ \\
\hline HR overlap ${ }^{a}$ & overlap of animal's home range (HR) & $\begin{array}{l}\text { HR of each animal in different periods using kernel density } \\
\text { estimation in "adehabitatHR" R-package (Calenge, 2006) }\end{array}$ & $\begin{array}{l}\text { Pig-pig: } 0.48[0.02,0.95] \\
\text { Pig-cattle: } 0.29[0.04,0.62] \\
\text { Pig-pig: } 162.1[12,\end{array}$ \\
\hline$H R$ distance $e^{\mathrm{a}}$ & $\begin{array}{l}\text { distance between the medians of latitude and longitude of } \\
\text { two animals }\end{array}$ & See Description & $\begin{array}{l}3239.11] \\
\text { Pig-cattle: } 839.12[190.52, \\
1470.49]\end{array}$ \\
\hline Feeds $s^{\mathrm{a}}$ & $\begin{array}{l}\text { a binary variable indicating whether cattle supplements } \\
\text { were deployed and available for consumption }\end{array}$ & No feeding before Jun. $5^{\text {th }}, 2017$; feeding after Jun. $5^{\text {th }}, 2017$ & $\begin{array}{l}\text { Pig-pig \& Pig-cattle: feeding } \\
=1 ; \text { no feeding }=0\end{array}$ \\
\hline $\begin{array}{l}\text { Distance to } \\
\quad \text { supplements }\end{array}$ & $\begin{array}{l}\text { the Euclidean distance from the medians of latitude and } \\
\text { longitude within the animal's HR to the nearest } \\
\text { supplement }\end{array}$ & See Description & $\begin{array}{l}\text { Pig-pig: } 317.85 \text { [273.92, } \\
\text { 3323.33] } \\
\text { Pig-cattle: } 389.92 \text { [303.87, } \\
\text { 584.78] }\end{array}$ \\
\hline Supplement density ${ }^{\mathrm{a}}$ & $\begin{array}{l}\text { the mean number of supplements per } \mathrm{km}^{2} \text { within the HRs } \\
\text { of each pair of animals } \\
\text { a factor with levels representing different time windows }\end{array}$ & See Description & $\begin{array}{l}\text { Pig-pig: } 2.44[0.13,3.27] \\
\text { Pig-cattle: } 1.97[1.29,3.63]\end{array}$ \\
\hline Period $^{\mathrm{a}}$ & $\begin{array}{l}\text { when cattle were grazing in nine different pastures or } \\
\text { combinations thereof }\end{array}$ & See Description & See Table S2 \\
\hline Overlap time ${ }^{a}$ & $\begin{array}{l}\text { the number of days that the pair of animals had } \\
\text { concurrent, active GPS collars within each time window } \\
\text { associated with cattle management actions }\end{array}$ & See Description & $\begin{array}{l}\text { Pig-pig: } 22[5,28] \\
\text { Pig-cattle: } 24[8,28]\end{array}$ \\
\hline distance to pixel ${ }^{\mathrm{b}}$ & $\begin{array}{l}\text { a vector of the average distance between HR centroids of a } \\
\text { pair of animals and their contact locations in each time } \\
\text { window }\end{array}$ & See Description & $\begin{array}{l}\text { Pig-pig: } 350.78 \text { [68.65, } \\
\text { 3544.06] } \\
\text { Pig-cattle: } 525.17 \text { [218.16, } \\
\text { 1023.47] }\end{array}$ \\
\hline $\begin{array}{l}\text { Molasses/ mineral/ } \\
\quad \text { water feeding days }^{\mathrm{c}}\end{array}$ & $\begin{array}{l}\text { a vector to consider the availability of different feeding } \\
\text { resources during the time period that the contact data } \\
\text { were aggregated }\end{array}$ & $\begin{array}{l}\text { the product of the resource available time and the number of } \\
\text { active molasses, mineral station, or water troughs in each time } \\
\text { window since feeds were deployed }\end{array}$ & $\begin{array}{l}\text { Pig-pig (water): } 40 \text { [10,100] } \\
\text { Pig-pig (mineral): } 36 \\
\text { [24,75] } \\
\text { Pig-pig (molasses) } 30 \\
\text { [16,46] } \\
\text { Pig-cattle (water): } 20 \text { [0,55] } \\
\text { Pig-cattle (mineral): } 18 \\
\text { [0,25] } \\
\text { Pig-cattle (molasses): } 20 \text { [0, } \\
\text { 50] }\end{array}$ \\
\hline
\end{tabular}

Note:

${ }^{a}$ Variables were considered in all model sets.

b Variables were only considered in the cell-level contact rates related model sets.

c Variables were only considered in the supplement induced contact related model sets and the model set of wild pig's visitation to cattle supplements.

occurrence between two individuals and the number of contacts over time, respectively. Both components include individual random effects. A negative binomial hurdle model was also tested initially but had lower model performance than the Poisson model. We built separate models for pig-pig and pig-cattle direct contact.

We incorporated sex pair, overlap time, home range (HR) distance, $H R$ overlap, supplement density, distance to supplement, feed, and period with random effects into the model to quantify pig-pig and pig-cattle direct contacts. It should be noted that in the Poisson component of the hurdle model, the variable overlap time was treated as an offset for estimating contact rates.

\subsubsection{Inferring natural resource-mediated indirect contact}

To estimate the effects of different factors on pig-pig and pig-cattle natural resource-mediated indirect contacts across the study area, we first followed the aforementioned modeling approach with the same set of covariates as used in quantifying direct contact. We then examined variation in pairwise contact rates at the grid-pixel level to investigate the spatial heterogeneity of natural resource-mediated indirect contacts across the landscape.

We specified a conditional autoregressive (CAR) model assuming that the observed counts of natural resource-mediated indirect contact events, $Y_{i, m, n}$, for each pair of animals, $m$ and $n$, at the respective area $i$, are Poisson distributed with the parameter $\lambda_{i, m, n}$.

$Y_{i, m, n}=\operatorname{Poisson}\left(\lambda_{i, m, n}\right)$ 
$\log \left(\lambda_{i, m, n}\right)=\beta X+\log ($ offset $)+\mu_{i}+v_{m}+v_{n}$

where $X$ is the matrix of covariates and $\beta$ is the coefficient matrix of these covariates; $\mu_{i}$ is a spatially-structured component modeled using a CAR

distribution with Gaussian Markov random fields (GMRFs) as priors, $\mu_{i} \mid$ $\mu_{j \neq i} \sim N\left(\frac{\sum_{j \in N(i)} \mu_{j}}{\# N(i)}, \frac{\sigma_{\mu}^{2}}{\# N(i)}\right)$; \#N(i) is the number of areas which share boundaries with the $\mathrm{i}^{\text {th }}$ grid (Rue and Held, 2005); $v_{m}$ and $v_{n}$ are the non-spatial individual random effects for animal $m$ and $n$, which were specified as a set of vague normal priors (i.e. $\log _{v_{m}, v_{n}}, \log _{\mu} \sim \log \operatorname{Gamma}(1,0.0005)$ ). A full description of CAR modelling theory can be found elsewhere (Banerjee et al., 2014; Gelfand and Vounatsou, 2003).

The neighborhood matrix between contact-event locations was generated based on a Voronoi tessellation for a point process in which the tiling of the locations results in the formation of natural neighbors defined by the adjoining edges of tile (Lawson, 2012; Okabe et al., 2008). Thus, two locations that shared Voronoi tessellation boundaries were considered neighbors.

We included distance to supplements, supplement density, HR distance, HR overlap, sex pair, overlap time, feeds, and period, with an additional distance to pixel in the covariate set to estimate the spatial variation of the pixel-level pairwise contact rates. Similarly, the variable overlap time served as an offset. The CAR models with all possible covariate combinations were implemented using integrated nested Laplace approximations (INLA; Rue et al., 2009) in "R-INLA" package (Lindgren and Rue, 2015) with the Besag model for spatial effects specified inside the function and two identically independent random effects for the pair of contacting animals (Blangiardo and Cameletti, 2015). We calculated partial $\mathrm{R}^{2}$ for spatial (CAR component), individual (random effect), and fixed effects in the top-selected models to estimate their marginal contributions on explaining the variation.

To directly compare the rates for pig-pig and pig-cattle direct and natural resource-mediated indirect contact, we scaled the predictions from the final models and presented them as the average per animal contact rate per $\mathrm{km}^{2}$ (i.e. number of contacts per animal per $\mathrm{km}^{2}$ ). Specifically, the direct contact rates were scaled using the node-level strength centrality from the predicted contact network divided by the areas of animals' HRs, where the network edges were weighted by the predicted number of contacts per day. Natural resource-mediated indirect contact rates were scaled by high-use areas identified based on the gridded probability surface of visitation rates.

\subsubsection{Supplement-mediated indirect contact}

We employed a Poisson hurdle model with a multinomial hurdle component (Yang et al., 2021) to quantify the influence of different factors on indirect contact via different types of cattle resources (molasses/mineral stations or water troughs) across the study area. Variables included in this analysis were distance to supplement, supplement density, HR distance, HR overlap, overlap time, period, and sex pair, with an additional feeding days. Similarly, overlap time served as an offset in the Poisson component to adjust for the rates of supplement-mediated indirect contact in each time window.

\subsubsection{Wild pig usage of cattle supplements}

To better understand how particular supplementation practices might affect wild pig-cattle contact rates, we examined factors that affect wild pig visitation rates to water troughs and mineral/molasses stations. We used a zero-inflated Poisson model (see model specification in Supplementary Information 2) to estimate the number of wild pig visitations to different types of cattle resources. Here, the contact pair was the unique pig-cattle pair per supplement location. As covariates, we considered the spatial proximity and sex of wild pigs using different stations as well as the availability dynamics of the cattle resources (specific covariates were: distance to supplement, sex, period, refill, molasses feeding days, mineral feeding days, water feeding days, supplement density, and overlap time). Distance to supplement, sex, period, supplement density, and overlap time were as described previously. Overlap time served as an offset in the Poisson distribution of the model to adjust for the rates of wild pig visitation to supplements in each time window. Refill was a dummy variable indicating if the supplement station has been refilled or not. The variables molasses feeding days, mineral feeding days, and water feeding days represent the product of the resource availability time and the number of active supplement sites of molasses, mineral stations, and water troughs, respectively.

Additionally, we employed parametric survival analysis to estimate how long the wild pigs returned to the cattle resource sites regularly after they found the resource. Survival analysis has been developed to evaluate times until an event of interest, e.g., death, occurs (Lee and Go, 1997). Here, we calculated the survival time as the number of days until wild pigs stop using a cattle resource site (right-censored observations) and assumed it to follow a Weibull distribution (tested Weibull, log-normal, and normal distributions and selected Weibull based on WAIC). We incorporated the above covariate sets for estimating wild pig's visitation rates to cattle resources and generated different variable combinations.

We fit all models (Poisson hurdle models, zero-inflated Poisson models, and survival models) using Bayesian Markov chain Monte Carlo (MCMC) methods using JAGS v4.3.0 (Plummer, 2003) and "jagsUI" R-package (Kellner, 2015). We ran 3 MCMC chains for 60,000 iterations, with a burn-in of 30,000 iterations and a thinning rate of 3 . We assessed the convergence of the model and sufficient burn-in by ensuring that the Gelman-Rubin statistic $\widehat{R}<1.05$ for all covariates and visually inspecting the trace plots (Gelman and Rubin, 1992). We generated all additive combinations of covariates and compared the model performance based on widely applicable information criteria (WAIC; Gelman et al., 2014). We used the AUC/ROC (areas under the curve of receiver operating characteristic) and one-to-one line $\mathrm{R}^{2}$ to assess the predictive accuracy for the binomial hurdle component and Poisson component of the model, respectively. We followed these criteria to compare and assess model performance to test the importance of different covariates at explaining different types of contact structure for all sets of analyses (Tables S3-7). All analyses were implemented in R v3.6.0 ( $R$ Core Team, 2019).

\section{Results}

\subsection{Magnitude and variation in contact rates}

Overall, the predicted pig-pig direct contact rate per animal per day per $\mathrm{km}^{2}$ was over twenty times higher than pig-cattle direct contact rate (3.29 with $95 \%$ prediction intervals of $[0.1,32.14]$ VS. 0.13 [0.04, 0.53 ; Fig. $2 A \& B$ ), with correspondingly more variations. The daily pigpig natural resource-mediated indirect contact rates per $\mathrm{km}^{2}$ had higher median values (7-day interval: 32.62 [1.00, 914.17]; 30-day interval: $44.73[0.86,1190.73])$ than the daily pig-cattle natural resourcemediated indirect contact rates (7-day interval: 21.65 [0.68, 178.82]; 30-day interval: 32.45 [0.72, 282.43]), with larger variation (Fig. 1; Fig. 2C\&D). There was minor spatial overlap between pig-pig and pigcattle natural resource-mediated indirect contact, as the collared cattle were not often moved to northern pastures during the study period (pigpig in the north; pig-cattle in the south). Some areas near molasses supplements had high rates for both pig-pig and pig-cattle natural resource-mediated contacts (Fig. 2E\&F).

\subsection{Effects of spatial covariates and supplementation on direct and natural resource-mediated indirect contact rates}

The models with the lowest WAIC were used to describe and compare pig-pig and pig-cattle direct contact (Model 5 in Table S3) and pig-pig 
and pig-cattle natural resource-mediated indirect contact with either a 7-day or 30-day interval (Model 1 in Table S3). For spatial heterogeneities of contact rates, model performance (WAIC scores in Table S4) suggested different model structures described pig-pig and pig-cattle natural resource-mediated indirect contacts for both 7-day and 30-day intervals, at the pixel-level (i.e. Model 8, Model 3, Model 6, and Model 2 were the top-selected models for pig-pig natural resourcemediated indirect contact with a 7-day interval, pig-pig natural resource-mediated indirect contact with a 30-day interval, pig-cattle natural resource-mediated indirect contact with a 7-day interval, and pig-cattle natural resource-mediated indirect contact with a 30-day interval, respectively; Table S4).

Spatial proximity between individuals significantly affect the rates of different types of contacts among wild pigs and between wild pigs and cattle (except for pig-cattle direct contact), with a negative correlation of HR distance and positive correlation of HR overlap (Fig. 3A\&B; Figs. S1 $A \& B ; S 2$ A\&B; S3 C\&D). When the HR distance was less than $1.04 \mathrm{~km}$, the daily pig-cattle natural resource-mediated indirect contact rates per $\mathrm{km}^{2}$ was predicted as 426.23 [306.74, 590.62] within a 7-day interval increasing to 1286.54 [870.64, 1897.65] within a 30-day interval, and the 7-day natural resource-mediated indirect contact rates in wild pigs was 241.62 [219.20, 266.41] per day per $\mathrm{km}^{2}$ (most should be associated with within-sounder contacts given the distance ranges $0-1.04 \mathrm{~km}$ ). The daily direct contacts were much lower than natural resourcemediated indirect contacts, with pig-pig direct contact rates of 4.48 $[0.89,22.08]$ contacts per $\mathrm{km}^{2}$ per day and pig-cattle as $0.1[0.06,0.18]$ contacts per $\mathrm{km}^{2}$ per day (Fig. $3 \mathrm{~A}$ ).

Distance to supplements determined the daily rates of natural resource-mediated indirect contact, while it did not affect direct contact. The natural resource-mediated indirect contact among wild pigs at 7day and 30-day intervals first decreased from daily rates of 185.07 [89.08, 384.52] and 159.29 [144.42, 175.68] per animal per $\mathrm{km}^{2}$ to $1.85[0.89,3.84]$ and $8.24[7.47,9.1]$, when the wild pigs were close to the supplements, however, the rates then increased to 161.71 [77.37, $337.98]$ and 88.56 [79.76, 98.32], respectively, when the HR distance to supplement sites was over $1.48 \mathrm{~km}$ (Fig. 3C). The daily pig-cattle natural resource-mediated indirect contact rates per animal per $\mathrm{km}^{2}$ with a 30 day interval decreased from 303.84 [214.70, 428.80] to below 1 with increasing distance to the supplements.

The average distance from the HRs of a pair of animals to their contact event location was a major factor influencing both pig-pig and pig-cattle natural resource-mediated indirect contacts (Figs. 3D \& S3A).
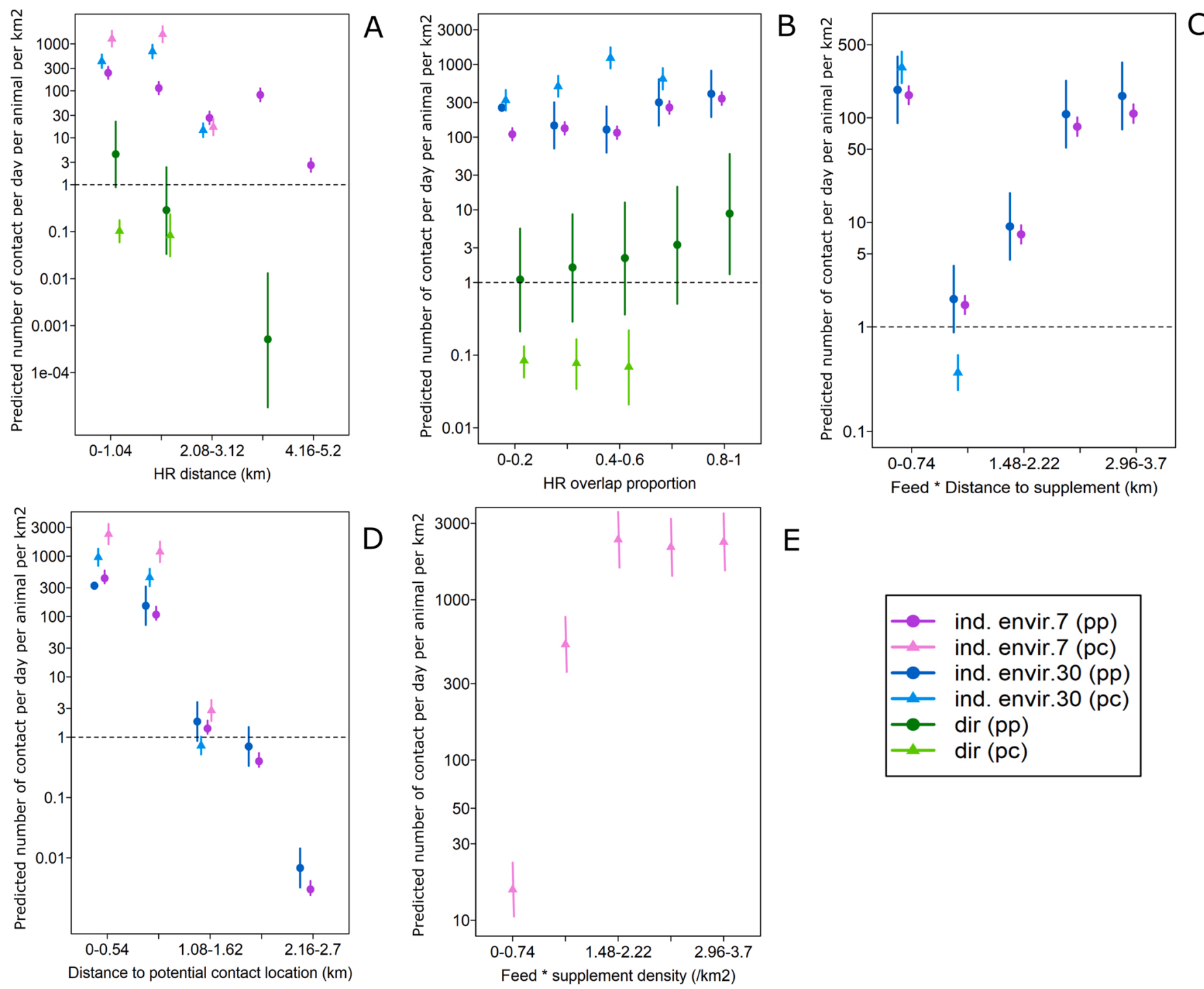

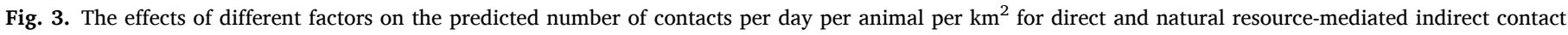

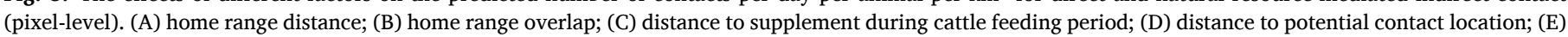

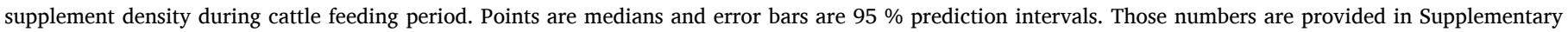
information 3. 
When the distance to the potential contact location was less than 0.54 $\mathrm{km}$ (Fig. 3D), the predicted pig-cattle natural resource-mediated indirect contact within 7-days and 30-days ranged at 1571.47-3418.74 and 693.17-1332.50 per day per $\mathrm{km}^{2}$, respectively, which was over double that of pig-pig natural resource-mediated indirect contact per day per $\mathrm{km}^{2}$ (7-day: [391.86, 474.55]; 30-day: [294.55, 356.87]). Both the pigpig and pig-cattle natural resource-mediated indirect contact had significant spatial heterogeneities and neighborhood effects, since the partial $\mathrm{R}^{2}$ suggested that spatial terms explained most of the variations
(Table S4)

\subsection{Effects of supplement availability dynamics on supplement-mediated indirect contact}

Model 3 was the top model (Table S5) describing the structure of pigpig supplement-mediated indirect contacts within both 7-day and 30day time intervals. Models 2 and 5 were the top-selected models for pig-cattle supplement-mediated indirect contact within the 7-day and
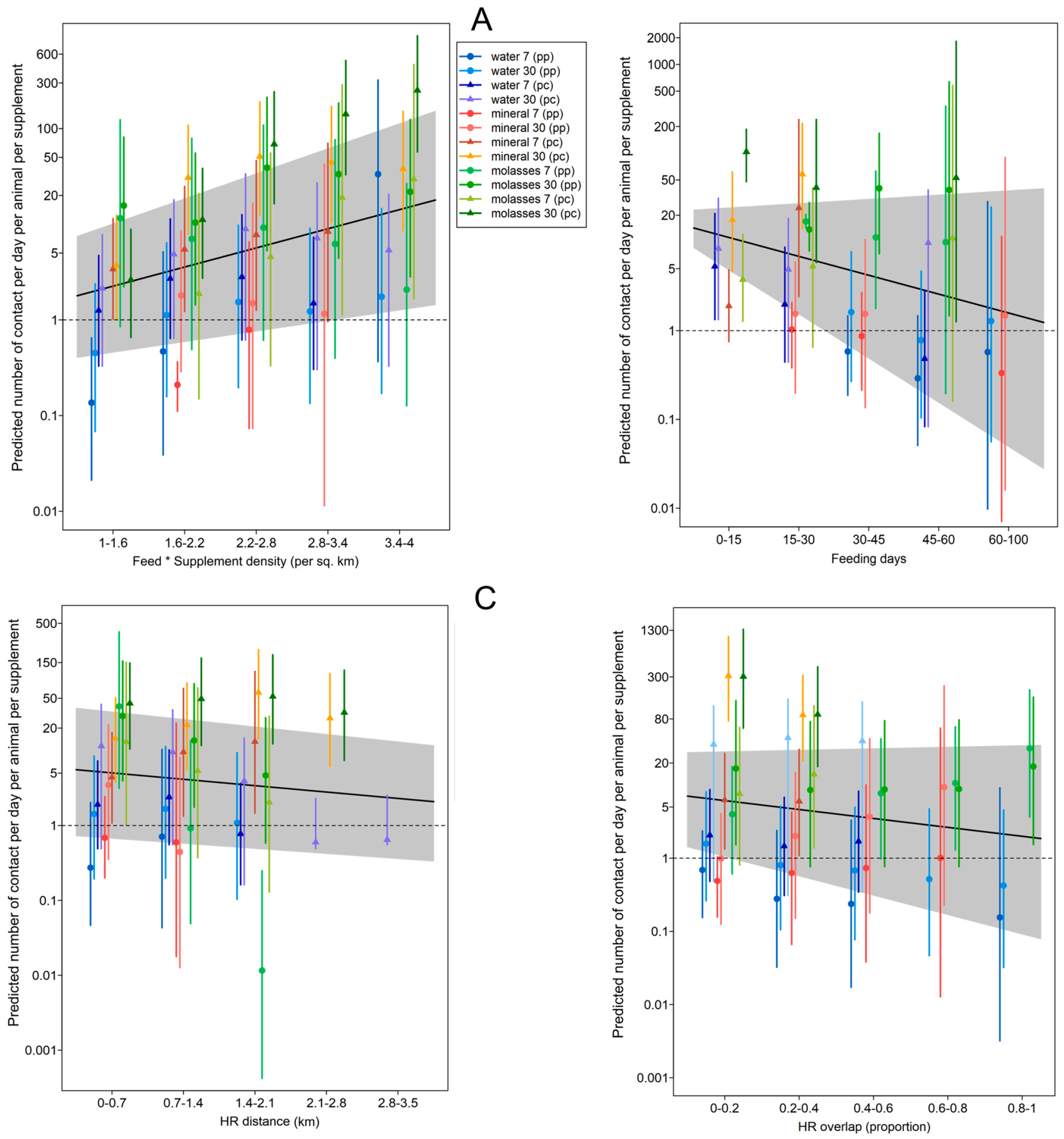

C

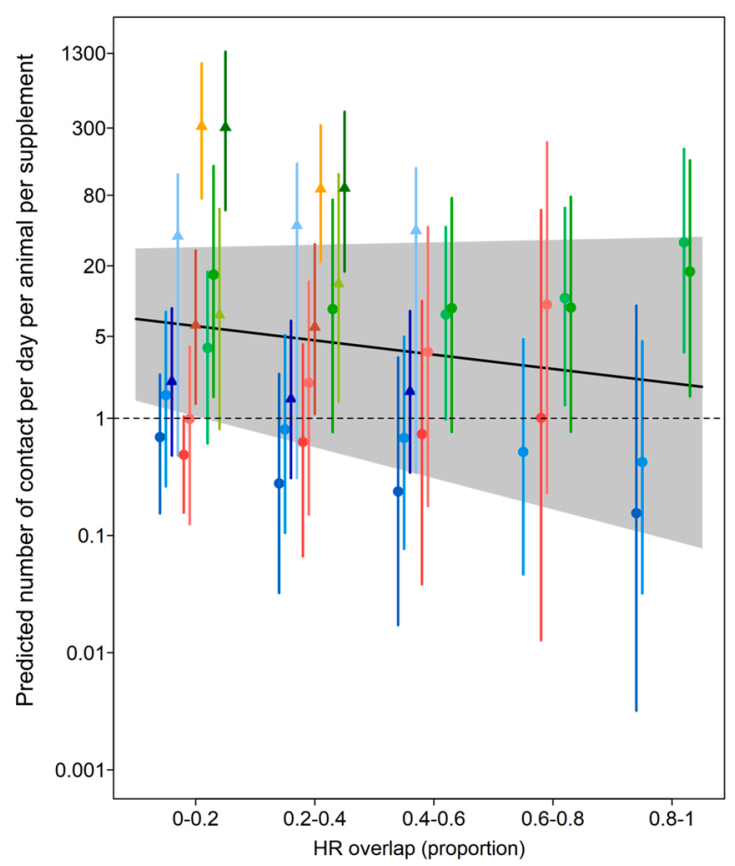

Fig. 4. The effects of different factors on the predicted number of indirect contacts per day per animal per supplement site on the landscape. (A) Supplement density per $\mathrm{km}^{2}$ (prediction from Model 3); (B) The total number of feeding days (availability) for each supplement site (prediction from Model 3 in Table S5); (C) Distance between home range centroids of the pair of animals making indirect contact at a supplement site (prediction from Model 3 in Table S5); (D) Home range overlap of the pair of animals making indirect contact at a station (prediction from Model 2 in Table S5). Points are medians and error bars are $95 \%$ prediction intervals. Those numbers are provided in Supplementary information 4. 
30-day time intervals, respectively. We focused on the effects of different factors on the predictions from Model 2 and 3 (Fig. 4; Fig. S4) and compared the functional responses across Models 2, 3, and 5 (Figs. S5-8).

Overall, more predicted daily indirect contacts per supplement site per animal among wild pigs (daily rates at 7-day interval: 33.28 [6.99, 356.67]; 30-day: 70.73 [10.9, 496.59]) and between wild pig and cattle (7-day: 27.27 [2.02, 501.38]; 30-day: 205.31 [50.71, 1253.55]) occurred via molasses, compared to water (7-day pig-pig: 2.30 [0.27, 27.78]; 30-day pig-pig: 3.84 [0.45, 30.57]; 7-day pig-cattle: 6.34 [1.49, 26.85]; 30-day pig-cattle: 18.64 [4.85, 69.99]) and minerals (7-day pigpig: 1.88 [0.40, 21.78]; 30-day pig-pig: 4.97 [0.42, 72.88]; 7-day pigcattle: 28.30 [3.99, 226.82]; 30-day pig-cattle: 102.37 [24.82, 381.14]; Fig. 4). The daily number of indirect contacts via each supplement per animal increased with increasing supplement density in an animal's HR, except for pig-pig indirect contact via molasses with a 7day interval (Fig. 4A; Fig. S5A). An increasing number of feeding days increased the daily number of indirect contacts via molasses on average, but the opposite was true for indirect contact via other cattle resources (especially pig-cattle contact via water), which generated an overall decreasing trend with increasing variance (Fig. 4B; Figs. S5-8). In general, there were more supplement-mediated indirect contacts when animals were in closer spatial proximity (i.e. closer distance or more overlap between HRs), however, the 7-day and 30-day pig-cattle indirect contact via minerals and the 30-day pig-cattle indirect contact via molasses showed opposite trends (Fig. 4C-D; Figs. S5-8).

\subsection{Factors affecting wild pig visitation rates to cattle supplements}

We selected Model 1 (model structure includes distance to supplement, period, refill, molasses feeding days, mineral feeding days, water feeding days, and supplement density) with the lowest WAIC score from Table S6 to estimate the characteristics of wild pig visitation to different types of supplements. We used Model 1 (model structure includes only distance to supplements; the most parsimonious model from competing models) from Table S7 to demonstrate their continuous usage of the supplements after the resources were found. Wild pigs preferred the stations/water troughs that were closer to their HR and that were refilled, especially the molasses stations (Fig. 5A-B). With the increasing feeding days, the predicted visitations to molasses stations were higher than water trough and mineral stations. Wild pigs tended to stop using the supplements sooner when the supplements/water troughs were deployed closer to their HR centroids (Fig. 5C).

\section{Discussion}

Disease emergence and transmission at the wildlife-livestock interface is often a dynamic process with spatial variation in where these processes occur on the landscape. Although often overlooked, it is important to characterize the spatial variation of intra- and inter-specific contact rates, which can structure the transmission process between wildlife and livestock. Here, we employed GPS data and a type of continuous-movement model to estimate the rate of three types of contact (direct contact, natural resource-mediated indirect contact, and supplement-mediated indirect contact) between wild pigs and cattle to infer the potential for disease transmission and management of pathogen spillover in this wildlife-livestock system.

Our study provided estimates and probability density functions for the daily rates of direct and natural resource-mediated indirect contacts per animal pair and/or per unit area (Fig. 2). Those estimates can be directly used to parameterize spatially-explicit epidemiological models of disease transmission rates (i.e., transmission rate $=$ contact rate $\mathrm{x}$ transmission probability given contact; Craft, 2015). Although the transmission probability given contact would be needed for absolute quantification of disease spread, using our estimates of contact rate variation across space (multiplied by a scaling parameter to represent transmission probability given contact) would provide realism in the qualitative dynamics of spatial spread.

Additionally, we estimated the effects of different factors on the three types of contacts in the wild pig and cattle systems and presented predictions of the standardized contact rates (i.e. the number of contacts per animal per day per $\mathrm{km}^{2}$ ) based on each type of contact (Figs. 3,4; see numbers in Supplementary information 3). This daily contact per capita per unit area information can be employed in spatially-explicit disease dynamic models to establish the optimal spatial distribution of control activities by accounting for spatial variation in contact rates through different pathogen transmission pathways.

Regarding the factors that influence direct and natural resourcemediated contact, our findings confirmed that direct contact rates (pig to pig) within the wild pig population decayed with the increasing spatial proximity between individuals (Fig. 3A-B), indicating potential constraints of spatial spread of diseases (see detailed discussion on this elsewhere; Pepin et al., 2016; Podgórski et al., 2018; Yang et al., 2021). However, this constraint on disease spread among wild pigs might be disrupted by natural resource-mediated indirect contacts. The high rates and wide geographical distribution of natural resource-mediated indirect contacts suggested that this mechanism could be a substantial
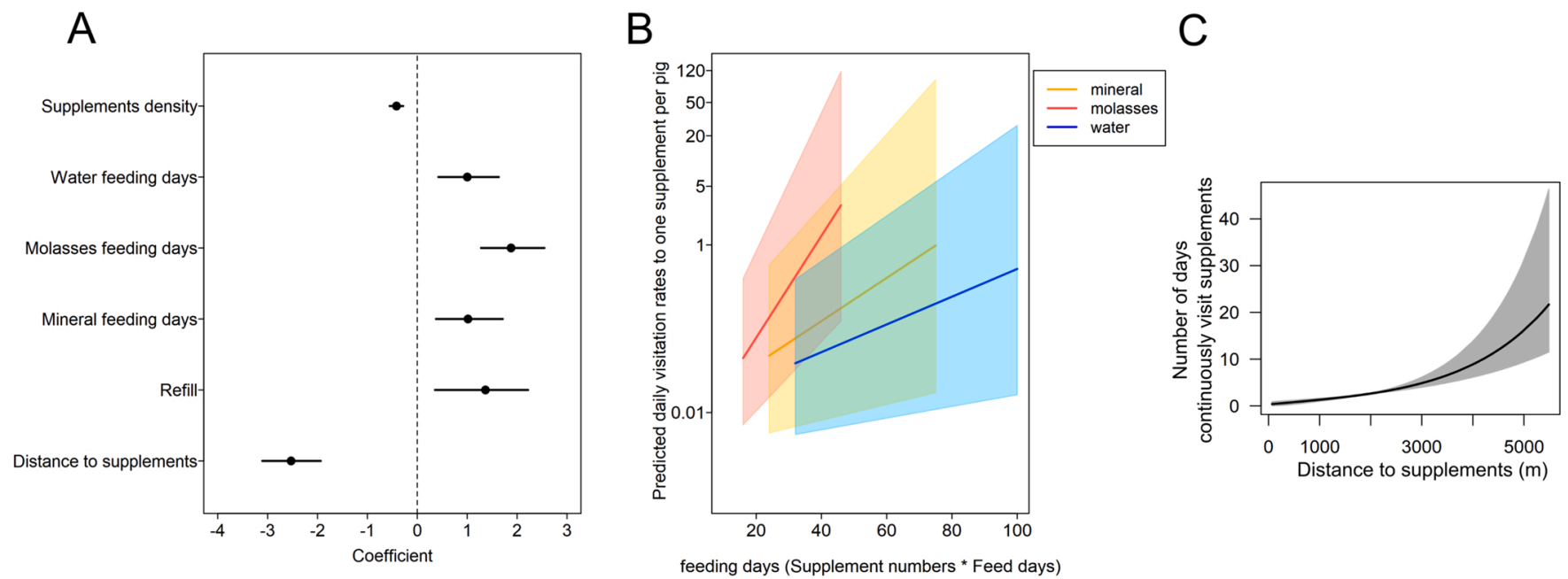

Fig. 5. (A) Top-selected zero-inflated Poisson (ZIP) model coefficient estimates with $95 \%$ credible intervals; (B) ZIP functional response curves of the predicted relationship between wild pigs' visitations and the number of feeding days of different types of supplements; (C) functional response from the survival model to estimate the effects of distance to supplement site on the number of days that wild pigs continuously visited the site after the resources were found. 
contributor to pathogen spread for pathogens that persist for 7 days and 30 days in the environment. Importantly, natural resource-mediated indirect contacts were only moderately limited by spatial proximity between individuals (Fig. 3A-B; minor effects of HR overlap; the occurrence of contact events at HR distance $>4.16 \mathrm{~km}$ despite the low rates), indicating risk of transmission between individuals even when their activity space was far apart and largely spatially segregated. Thus, an extensive spatial window might be needed to control indirect transmission among wild pigs.

We also found the distance to supplements influenced pairwise pigpig natural resource-mediated indirect contact with a negative correlation despite the large credible intervals (Fig. S3B), which indicated high indirect transmission risk near those sites. However, when the distance was greater than $1.48 \mathrm{~km}$, the predicted daily rates of natural resourcemediated contact per animal per $\mathrm{km}^{2}$ (Fig. 3C) increased with the increasing distance to supplements. This unintuitive pattern appeared to result from a sampling artifact in our study. Specifically, six wild pigs on the northwestern corner or western part of the study areas settled outside the ranch but made extensive forays to use cattle pastures. Such system specific resource driven movement patterns can create dynamics that are difficult to predict

When assessing interactions between pigs and cattle, we found pigcattle direct contact rates were $\sim 0.15$ times per day per animal pair and were not well explained by any of the covariates we examined (Fig. 2; Fig. 3A-B). However, the natural resource-mediated indirect contact rates between wild pigs and cattle were high and widely distributed across the cattle pastures. Similar findings were also reported in Cooper et al. (2010). Avoidance among species (Sinclair, 1985) and the different spatiotemporal habitat preference profiles among the species may explain the rare direct and high rates of indirect interspecific interactions. Wild pigs favor shade and dense cover of wetlands given their need for thermoregulation during hot periods (Garza et al., 2018), similarly cattle in the sub-tropical environment of this study site extensively visit and use wetlands to cool during the day (Pandey et al., 2009) and are forced to extend grazing into the night as the heat during the middle of the day limits their grazing time (Schottler et al., 1975). This similar use of cooling habitat likely contributes to the strong indirect contact rates observed. Management actions that reduce the potential for commingling between wild pigs and cattle and prevent the usage of cattle pastures by wild pigs could minimize the opportunity of pathogen spillover (Sokolow et al., 2019).

Prioritizing exclusion of pigs at molasses will be an effective intervention for decreasing additional indirect contacts due to anthropogenic resources. Our findings indicated that artificial food sources on the landscape can serve as another major source of indirect contact, especially via molasses supplements on the ranch due to the preference of wild pig's visitation to molasses feeds (Fig. 5). Wild pigs were also found to prefer supplements/water troughs deployed closer to their HR (Fig. 5A), which indicated that avoiding deployment of cattle supplements near habitats wild pigs use may help limit the supplementmediated indirect transmission. Although the practical fence design to only allow cattle to access feeding stations/water troughs is difficult to implement (Barasona et al., 2013), some recent sensor technology that can identify individual cattle, capture weights via dynamic weighing, and automatically identify individuals might help for managing cattle and fence design (González et al., 2014). Wild pigs tend to not visit areas with high density of cattle resources, which may be because those areas were highly occupied by cattle and there was general interspecific avoidance between the two species. Continuous usage of cattle resources even increased when the HR distance of wild pigs was far from those resources suggesting that the individuals settled outside the ranch and commuted to cattle resources (see previous discussion).

There are several factors that structure the generalizability of presented results. The study period mostly covered the wet season (May Oct) when natural resources and forage were abundant (Boughton and Boughton, 2014). Although wild pigs' behavioral changes in response to landscape heterogeneity and resource availability (Keuling et al., 2009), we may expect different contact patterns in the dry season when food is limited (for example, likely higher indirect contact rates via supplements). Additionally, natural resource-mediated contacts were identified conservatively, using high-use areas of the visitation rate surface to ensure the contacts considered here were epidemiologically relevant. Different structures of natural resource-mediated indirect contact can be found given different definitions, such as based on space use or behavioral states (Cooper et al., 2010; Lavelle et al., 2016). Further work to compare and validate these definitions and approaches in multiple systems would be valuable for accurately quantifying baseline indirect contact in the natural environment. Moreover, although our study suggested significant spatial heterogeneity and neighborhood effects on natural resource-mediated contacts, to further understand mechanisms underpinning the spatial variations, it is essential to characterize the environmental factors that drive the spatial patterns of contact occurrence and influence rates in future studies.

\section{Conclusion}

Our data and findings quantified the amount of spatial heterogeneity in intra- and inter-specific contact networks between wild pigs and cattle in south-central Florida. Our estimates of absolute direct and indirect contact rates (provided in units of per animal pair per $\mathrm{km}^{2} /$ supplement) that can be used as inputs to epidemiological models for risk assessment and identifying optimal control strategies at the pig-cattle interface. Those absolute, standardized direct and indirect contact rates are currently elusive in the wildlife-livestock systems, especially for indirect contact via natural resources. Our results regarding the high rates of natural resource-mediated indirect contact in wild pigs, which were widely distributed across the landscape, indicated a potential for undermining social and spatial constraints of disease spread identified as relevant for direct contacts. Thus, management of disease within wild pig populations may require focusing on large areas. The predominance of natural resource driven indirect contact between wild pigs and cattle indicated that actions focusing on constraining cattle visitation to wild pig habitat may be important to prevent pathogen spillovers. Molasses induced more indirect contacts among wild pigs and between wild pigs and cattle than water troughs and mineral supplements due to the wild pigs' preference for molasses stations, suggesting that disease mitigation might best be targeted at molasses stations.

\section{Declaration of Competing Interest}

The authors report no declarations of interest.

\section{Acknowledgements}

The research was supported by the United States Department of Agriculture. Contributions of JCB were partially supported by the US Department of Energy under Award No. DE-EM0004391 to the UGA Research Foundation. The findings and conclusions in this publication are those of the authors and should not be construed to represent any official US Government determination or policy. Mention of commercial products or companies does not represent an endorsement by the US government. We appreciate the support from ABIR for allowing this work to be performed on the property. Wild pig capture and handling were conducted under approved University of Florida IACUC protocol 201808495.

\section{Appendix A. Supplementary data}

Supplementary material related to this article can be found, in the online version, at doi:https://doi.org/10.1016/j.prevetmed.2021.10 5423. 


\section{References}

Aune, K., Rhyan, J.C., Russell, R., Roffe, T.J., Corso, B., 2012. Environmental persistence of Brucella abortus in the Greater Yellowstone Area. J. Wildl. Manage. 76, 253-261.

Banerjee, S., Carlin, B.P., Gelfand, A.E., 2014. Hierarchical Modeling and Analysis for Spatial Data. CRC press.

Barasona, J.A., VerCauteren, K., Saklou, N., Gortazar, C., Vicente, J., 2013. Effectiveness of cattle operated bump gates and exclusion fences in preventing ungulate multi-host sanitary interaction. Prev. Vet. Med. 111, 42-50.

Bates, T.W., Thurmond, M.C., Carpenter, T.E., 2003. Description of an epidemic simulation model for use in evaluating strategies to control an outbreak of foot-andmouth disease. Am. J. Vet. Res. 64, 195-204.

Bevins, S.N., Pedersen, K., Lutman, M.W., Gidlewski, T., Deliberto, T.J., 2014. Consequences associated with the recent range expansion of nonnative feral swine. Bioscience 64, 291-299.

Blangiardo, M., Cameletti, M., 2015. Spatial and Spatio-temporal Bayesian Models With R-INLA. John Wiley \& Sons.

Boehm, M., Hutchings, M.R., White, P.C., 2009. Contact networks in a wildlife-livestock host community: identifying high-risk individuals in the transmission of bovine TB among badgers and cattle. PLoS One 4 e5016.

Boughton, E.H., Boughton, R.K., 2014. Modification by an invasive ecosystem engineer shifts a wet prairie to a monotypic stand. Biol. Invasions 16, 2105-2114.

Calenge, C., 2006. The package "adehabitat" for the R software: a tool for the analysis of space and habitat use by animals. Ecol. Modell. 197, 516-519.

Cooper, S.M., Scott, H.M., De la Garza, G.R., Deck, A.L., Cathey, J.C., 2010. Distribution and interspecies contact of feral swine and cattle on rangeland in south Texas: implications for disease transmission. J. Wildl. Dis. 46, 152-164.

Craft, M.E., 2015. Infectious disease transmission and contact networks in wildlife and livestock. Philos. Trans. R. Soc. B: Biol. Sci. 370, 20140107.

Cross, P.C., Edwards, W.H., Scurlock, B.M., Maichak, E.J., Rogerson, J.D., 2007. Effects of management and climate on elk brucellosis in the Greater Yellowstone Ecosystem. Ecol. Appl. 17, 957-964.

D'EON, R.G., Delparte, D., 2005. Effects of radio-collar position and orientation on GPS radio-collar performance, and the implications of PDOP in data screening. J. Appl. Ecol. 42, 383-388.

Drewe, J., O'connor, H., Weber, N., McDonald, R., Delahay, R., 2013. Patterns of direct and indirect contact between cattle and badgers naturally infected with tuberculosis Epidemiol. Infect. 141, 1467-1475.

Fine, A.E., Bolin, C.A., Gardiner, J.C., Kaneene, J.B., 2011. A Study of the Persistence of Mycobacterium bovis in the Environment Under Natural Weather Conditions in Michigan. Veterinary medicine international, USA, 2011.

Freund, J.D., 1981. The Effects of Environmental Fomites on the Survival of Pseudorabies Virus.

Garza, S.J., Tabak, M.A., Miller, R.S., Farnsworth, M.L., Burdett, C.L., 2018. Abiotic and biotic influences on home-range size of wild pigs (Sus scrofa). J. Mammal. 99, 97-107.

Gelfand, A.E., Vounatsou, P., 2003. Proper multivariate conditional autoregressive models for spatial data analysis. Biostatistics 4, 11-15.

Gelman, A., Rubin, D.B., 1992. Inference from iterative simulation using multiple sequences. Stat. Sci. 7, 457-472.

Gelman, A., Hwang, J., Vehtari, A., 2014. Understanding predictive information criteria for Bayesian models. Stat. Comput. 24, 997-1016.

Godfrey, S.S., 2013. Networks and the ecology of parasite transmission: a framework for wildlife parasitology. Int. J. Parasitol. Parasites Wildl. 2, 235-245.

González, L., Bishop-Hurley, G., Henry, D., Charmley, E., 2014. Wireless sensor networks to study, monitor and manage cattle in grazing systems. Anim. Prod. Sci. 54, $1687-1693$.

Hulbert, I.A., 2001. GPS and its use in animal telemetry: the next five years. Presented at the Proceedings of the Conference on Tracking Animals with GPS 51-60.

Johnson, D.S., London, J.M., Lea, M.-A., Durban, J.W., 2008. Continuous-time correlated random walk model for animal telemetry data. Ecology 89, 1208-1215.

Johnson, P.T., De Roode, J.C., Fenton, A., 2015. Why infectious disease research needs community ecology. Science 349.

Jones, B.A., Grace, D., Kock, R., Alonso, S., Rushton, J., Said, M.Y., McKeever, D., Mutua, F., Young, J., McDermott, J., 2013. Zoonosis emergence linked to agricultural intensification and environmental change. Proc. Natl. Acad. Sci. 110, 8399-8404.

Keiter, D.A., Mayer, J.J., Beasley, J.C., 2016. What is in a "common" name? A call for consistent terminology for nonnative Sus scrofa. Wildl. Soc. Bull. 40, 384-387.

Kellner, K., 2015. jagsUI: A Wrapper Around Rjags to Streamline JAGS Analyses. R Package Version 1.

Keuling, O., Stier, N., Roth, M., 2009. Commuting, shifting or remaining? Different spatial utilisation patterns of wild boar Sus scrofa L. in forest and field crops during summer. Mamm. Biol. 74, 145-152.

Kohmann, M.M., Saha, A., Silveira, M.L., Boughton, E.H., Swain, H., Brandani, C.B., 2021. Farm-scale phosphorus budgets of beef cow-calf operations. Nutr. Cycl. Agroecosyst. 1-15.

Kukielka, E., Barasona, J.A., Cowie, C.E., Drewe, J., Gortazar, C., Cotarelo, I., Vicente, J, 2013. Spatial and temporal interactions between livestock and wildlife in South Central Spain assessed by camera traps. Prev. Vet. Med. 112, 213-221.

Kunkle, W., Johns, J., Poore, M., Herd, D., 2000. Designing supplementation programs for beef cattle fed forage-based diets. J. Anim. Sci. 77.

Lavelle, M.J., Phillips, G.E., Fischer, J.W., Burke, P.W., Seward, N.W., Stahl, R.S., Nichols, T.A., Wunder, B.A., VerCauteren, K.C., 2014. Mineral licks: motivational factors for visitation and accompanying disease risk at communal use sites of elk and deer. Environ. Geochem. Health 36, 1049-1061.
Lavelle, M.J., Kay, S.L., Pepin, K.M., Grear, D.A., Campa III, H., VerCauteren, K.C., 2016. Evaluating wildlife-cattle contact rates to improve the understanding of dynamics of bovine tuberculosis transmission in Michigan, USA. Prev. Vet. Med. 135, 28-36.

Lawson, A.B., 2012. Bayesian point event modeling in spatial and environmental epidemiology. Stat. Methods Med. Res. 21, 509-529.

Lee, E.T., Go, O.T., 1997. Survival analysis in public health research. Annu. Rev. Public Health 18, 105-134.

Lewis, J.S., Corn, J.L., Mayer, J.J., Jordan, T.R., Farnsworth, M.L., Burdett, C.L., VerCauteren, K.C., Sweeney, S.J., Miller, R.S., 2019. Historical, current, and potential population size estimates of invasive wild pigs (Sus scrofa) in the United States. Biol. Invasions 21, 2373-2384.

Lindgren, F., Rue, H., 2015. Bayesian spatial modelling with R-INLA. J. Stat. Softw. 63, $1-25$.

Miller, R.S., Farnsworth, M.L., Malmberg, J.L., 2013. Diseases at the livestock-wildlife interface: status, challenges, and opportunities in the United States. Prev. Vet. Med. $110,119-132$.

Miller, R.S., Sweeney, S.J., Slootmaker, C., Grear, D.A., Di Salvo, P.A., Kiser, D., Shwiff, S.A., 2017. Cross-species transmission potential between wild pigs, livestock, poultry, wildlife, and humans: implications for disease risk management in North America. Sci. Rep. 7, 1-14.

Morris, L.R., Proffitt, K.M., Asher, V., Blackburn, J.K., 2016. Elk resource selection and implications for anthrax management in Montana. J. Wildl. Manage. 80, 235-244.

Okabe, A., Satoh, T., Furuta, T., Suzuki, A., Okano, K., 2008. Generalized network Voronoi diagrams: concepts, computational methods, and applications. Int. J. Geogr. Inf. Sci. 22, 965-994.

Pandey, V., Kiker, G., Campbell, K., Williams, M., Coleman, S., 2009. GPS monitoring of cattle location near water features in South Florida. Appl. Eng. Agric. 25, 551-562.

Patz, J.A., Epstein, P.R., Burke, T.A., Balbus, J.M., 1996. Global climate change and emerging infectious diseases. JAMA 275, 217-223.

Pepin, K.M., Davis, A.J., Beasley, J., Boughton, R., Campbell, T., Cooper, S.M., Gaston, W., Hartley, S., Kilgo, J.C., Wisely, S.M., 2016. Contact heterogeneities in feral swine: implications for disease management and future research. Ecosphere 7, e01230.

Plummer, M., 2003. JAGS: a program for analysis of Bayesian graphical models using Gibbs sampling. In: Presented at the Proceedings of the 3rd International Workshop on Distributed Statistical Computing. Vienna, Austria, p. 10

Podgórski, T., Apollonio, M., Keuling, O., 2018. Contact rates in wild boar populations: implications for disease transmission. J. Wildl. Manage. 82, 1210-1218.

R Core Team, 2019. R: A Language and Environment for Statistical Computing. R Foundation for Statistical Computing, Vienna, Austria.

Rue, H., Held, L., 2005. Gaussian Markov Random Fields: Theory and Applications. CRC press.

Rue, H., Martino, S., Chopin, N., 2009. Approximate Bayesian inference for latent Gaussian models by using integrated nested Laplace approximations. J. R. Stat. Soc. Series B Stat. Methodol. 71, 319-392.

Schauber, E.M., Storm, D.J., Nielsen, C.K., 2007. Effects of joint space use and group membership on contact rates among white-tailed deer. J. Wildl. Manage. 71, 155-163.

Schoenbaum, M., Freund, J., Beran, G., 1991. Survival of pseudorabies virus in the presence of selected diluents and fomites. J. Am. Vet. Med. Assoc. 198, 1393.

Schottler, J., Efi, P., Williams, W., 1975. Behaviour of beef cattle in equatorial lowlands. Aust. J. Exp. Agric. 15, 725-730.

Schumaker, B.A., Peck, D.E., Kauffman, M.E., 2012. Brucellosis in the Greater Yellowstone area: disease management at the wildlife-livestock interface. Hum.Wildlife Interact. 6, 7.

Sinclair, A.R., 1985. Does interspecific competition or predation shape the African ungulate community? J. Anim. Ecol. 899-918.

Sokolow, S.H., Nova, N., Pepin, K.M., Peel, A.J., Pulliam, J.R., Manlove, K., Cross, P.C., Becker, D.J., Plowright, R.K., McCallum, H., 2019. Ecological interventions to prevent and manage zoonotic pathogen spillover. Philos. Trans. Biol. Sci. 374, 20180342 .

Swain, H.M., Boughton, E.H., Bohlen, P.J., Lollis, L.O., 2013. Trade-offs among ecosystem services and disservices on a Florida ranch. Rangelands 35, 75-87.

Triguero-Ocaña, R., Barasona, J.A., Carro, F., Soriguer, R.C., Vicente, J., Acevedo, P., 2019. Spatio-temporal trends in the frequency of interspecific interactions between domestic and wild ungulates from Mediterranean Spain. PLoS One 14 e0211216.

Wiethoelter, A.K., Beltrán-Alcrudo, D., Kock, R., Mor, S.M., 2015. Global trends in infectious diseases at the wildlife-livestock interface. Proc. Natl. Acad. Sci. 112, 9662-9667.

Wilber, M.Q., Pepin, K.M., Campa III, H., Hygnstrom, S.E., Lavelle, M.J., Xifara, T., VerCauteren, K.C., Webb, C.T., 2019. Modeling multi-species and multi-mode contact networks: implications for persistence of bovine tuberculosis at the wildlifelivestock interface. J. Appl. Ecol.

Wilson, R.R., Horne, J.S., Rode, K.D., Regehr, E.V., Durner, G.M., 2014. Identifying polar bear resource selection patterns to inform offshore development in a dynamic and changing Arctic. Ecosphere 5, 1-24.

Yang, A., Mullins, J.C., Van Ert, M., Bowen, R.A., Hadfield, T.L., Blackburn, J.K., 2020. Predicting the geographic distribution of the Bacillus anthracis A1. a/Western North 
American sub-lineage for the continental United States: new outbreaks, new genotypes, and new climate data. Am. J. Trop. Med. Hyg. 102, 392-402. Yang, A., Schlichting, P., Wight, B., Anderson, W.M., Chinn, S.M., Wilber, M.Q.,

Miller, R.S., Beasley, J.C., Boughton, R.K., VerCauteren, K.C., 2021. Effects of social structure and management on risk of disease establishment in wild pigs. J. Anim. Ecol. 90, 820-833.

zu Dohna, H., Peck, D.E., Johnson, B.K., Reeves, A., Schumaker, B.A., 2014.

Wildlife-livestock interactions in a western rangeland setting: quantifying diseaserelevant contacts. Prev. Vet. Med. 113, 447-456. 